\title{
Lecturer's Perception of Using an Analytical Rubric for Assessing Summary Writing
}

\author{
Melvy Nancilia Putri \\ Universitas Pendidikan Indonesia \\ Bandung, Indonesia \\ Melvy@upi.edu
}

\begin{abstract}
Assessment is truly essential in teaching writing skills. An analytical rubric is a common evaluation to find out the achievement of students' writing skills. However, a kind of rubric which is adopted to score summary writing is different from the general writing skill rubric. This study aimed at finding the lecturer's perception of using an analytical rubric in scoring summary writing. A qualitative case study was used as the research design which employed three data collection techniques consisted of pre-observation, interviews, and data analysis. After analyzing the data using an analytical rubric by Frey, Fisher, and Hernandez (2003), it was discovered that the rubric had a positive impact on the students' summary writing score. The lecturer believed that assessing students' summary writing by rubric scoring was able to enhance the students' skill in writing more concisely. Also, lecturers are suggested to be transparent in assessing students' writing using an analytical rubric.
\end{abstract}

Keywords: analytical rubric, assessment, lecturer's perception, summary writing

\section{INTRODUCTION}

Writing, in general, is known as the most difficult skill to learn. Foong (2017) states that learning how to write is important and useful for rhetorical practice and communication. Also, it is beneficial as a discovery as well as a cognitive process. Writing is important because writing is used to communicate ideas to others. It helps people to develop their thinking and reasoning skills, or develop an argument or position and support oral language development. It is used as a means of communication to convey knowledge or information about a given subject. For example, in the newspaper, the reader often finds the article, which consists of someone's opinion or the scientists' invention. The purpose is to share information. The function of writing also can be as selfexpression. When people feel sad or happy, they can express their feeling by writing it down in a diary. When people find a big innovation about things, they can write it down in a journal. People can also express their feelings or impression through a blog, then other people can read it and know what the authors feel. Those things prove that writing is a kind of selfexpression.

Speaking about writing, having a good ability in writing is not only about how to master the grammar but people also need to be experts in generalizing the idea to make other people, the readers, get the whole information by only reading the writing. In the teaching and learning process, writing is not easy. The difficulties are not only in organizing and generating ideas but these ideas into readable texts. The students have to pay attention to planning and organizing as well as spelling, punctuation, and word choice. It becomes the reason why the students have to master writing as their need. Based on the journal research of Spelkova and Hurst (2008) about teachers' attitudes to the skills and writing process in Latvia and Portugal, writing is the most difficult skill in English.

One of several writing skills that have to be adopted by college students is summary writing. Frey et al. (2003) have stated on a point that the ability to write summary tightly, concisely, and accurately is an essential entry point to other writing genres, especially analytical and technical writing. It is clearly understood that the students need to be able to summarize before they can be successful at most of the other kinds of writing that they will be familiar with in college life. Summary writing is also needed in daily life such as taking a note, explaining the movie stories to other people by writing, informing friends about the lessons they have missed today, and so on.

Mastering how to write a summary writing effectively might be the most essential writing skill college students can process. The purpose of summary writing is to shortly describe the whole information we got from the other sources to other people who read it so they do not need to reach the same sources to understand the materials.

Ausubel (1963) and Wichadee (2014) confirmed that when students can summarize effectively, they demonstrate their comprehension of the source text through writing. Furthermore, they have to decode what they read, make connections between what they read and their prior knowledge on the subject matter. The students who have good ability in summary writing will be more critical and having meaningful words.

Yet, in assessing summary writing, the lecturer needs a guide to see the achievement of students' summary writing skills. Assessment is a fundamental concern of all educational settings. Harmer (2007) has clearly stated that marks provide students with significant about their performance and progress and further enable outsiders to make decisions based on students' qualifications. This is reasonable that by checking marks and checklists, the lecturer or the teacher will find out whether the students have accomplished their goals.

Summary writing achievement will be greatly reached if the students know what exactly criteria they need to complete. The criteria for summary writing are different from the criteria of general writing. Summary's writing rubric is related to length, 
focus, conciseness, coherence, and cohesion as the criteria. However, the summary writing rubric itself has several kinds of form. It varies because of the way how to the lecturer scores the students' achievement in summary writing is different but still in line with the general criteria of summary writing.

There are several researchers had conducted this kind of major. Hendrian (2013) administered the research on assessing the accuracy of summary writing through the analytical rubric. $\mathrm{He}$ found that analytical rubric truly helped in assessing students' achievement. Besides, Kusmawati (2019) and Mozaffari (2013) also found that an analytical rubric can be also implemented in assessing another form of writing skills such as creative writing. It also can be used in assessing students' tasks via google platform kind of rubric.

Concerning this, a kind of analytical rubric which is going to be investigated in this study is the summary writing rubric used by one of the lecturers in University of Lampung. This case occurs to see whether the current rubric is effective to be implemented in class to assess the summary writing. Kind of rubric which is used in this case is the analytical rubric created by Frey et al. (2003) which consists of length, accuracy, paraphrasing, focus, and conventions.

This study was aimed at finding the lecturer's perception of why this analytical rubric is selected to be the tool to assess the students' summary writing skills.

\section{METHOD}

This research was intended to find out the lecturer's perception of using an analytical rubric in assessing the students' summary writing skills. A descriptive qualitative study was chosen since it was appropriate to give a complete description of the English lecturer in applying an analytical rubric for assessing students' summary writing skills. This study was conducted in one of the universities in Lampung.

This study employed qualitative purposeful sampling in which the participants were selected intentionally to understand the current phenomena. The participant in this study was an English lecturer who had been teaching for 2 years, especially in teaching writing. The instrument of the data collection was several questions related to summary writing which were interviewed to the lecturer to get valid data.

The researcher used some steps in collecting the data, first was selecting the participant as the sample, then doing preobservation to find out what kind of rubric they use in assessing the students' summary writing skill, next interviewing regarding the summary writing's rubric, and the last was analyzing the data to complete this research.

\section{FINDINGS AND DISCUSSION}

The researcher conducted pre-observation related to the topic. The pre-observation was done to obtain the data. In this step, the researcher asked the lecturer what kind of rubric she used to assess the students' summary writing. The lecturer gave the researcher an example of the analytical rubric. The rubric was created by Frey et al. (2003). This rubric has been used by her for about the last 1.5 years since she was obligated as an English lecturer.
During the interview, she explained why this rubric was selected to be the current rubric in scoring the students' achievement. She said that she once actually used different kinds of the rubric in this context but she found several perplexities that she was not sure that kind of rubric was able to help her in assessing the students' summary writing skill. In this interview, she also mentioned several lecturers using this rubric as the scoring assessment in teaching summary writing.

In line with this current issue, she said that writing a summary is quite difficult for most of the students because having the ability of general writing is not enough. In writing generally, the students only need to focus on content, grammar, mechanics, and organization without taking any concerns about the length and redundancy. However, summarizing needs other skills to make the writing easily readable, and understandable at the same time. The students need to also master the ability of conciseness, accuracy, staying on point of focus, conventions. These criteria of students' summary writing skills were included in the analytical rubric purposed by Frey et al. (2003). The rubric can be illustrated below:

\section{TABLE I. THE SUMMARY WRITING'S RUBRIC}

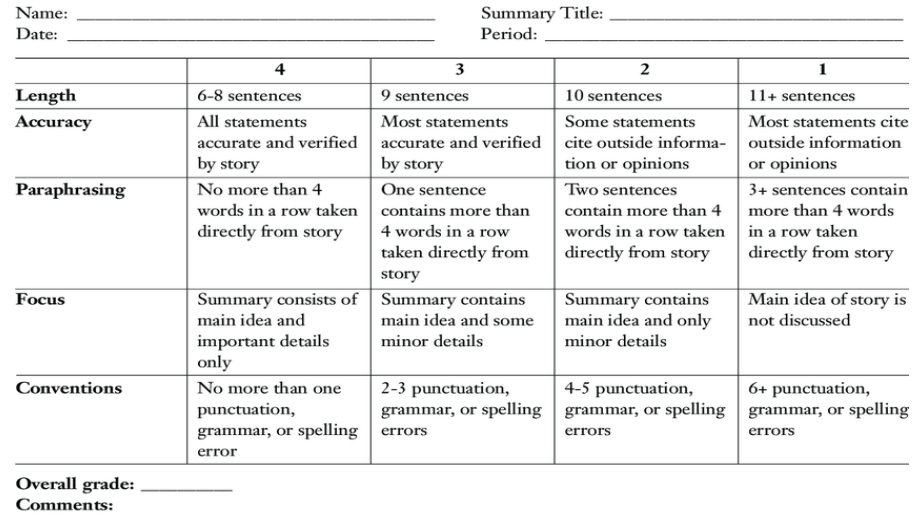

Table I. clearly shows the criteria the students need to concern in summarizing the writing. It also displays the levels of students' achievement in terms of summary writing. The next confession described by the lecturer during the interview is related to each of the summary writing criteria above.

a. Length: the very first thing the students need to pay attention to summarizing writing is the length. The longer their writing is, the worse their ability is in summary writing. In this case, the lecturer believed that the length is one of the most important criteria the students have to pay attention to. In summary writing, the length does matter because, in every reading activity, it is unavoidable that most people just want to quickly get the point of the context. When reading long writing, they will get bored and do skimming to exactly reach the main idea. However, many people do not master skimming skills because people need to practice and practice more in mastering this kind of reading ability. Therefore, the length of summary writing is needed to be concerned to ease people getting the main point only by reading the shorter text. 
b. Accuracy: this kind of criteria is used to score the accuracy of the students' summary writing. The accuracy of the writing is seen by the ability of the students to generalize the verified statements in a story. The lecturer said that this criterion is like a pole in summary writing because we can't understand the idea of the text without accuracy. It is needed to be achieved by the students to see their understanding of the source so they can transfer their knowledge to other people in their language to make the other people easier to get the point. The accuracy criteria are also beneficial to enhance the students' critical thinking ability because this criterion drills the students not only to re-write the source but also to convert the whole or brief idea of the very long text to the very simple sentences and paragraph. The students' summary writing is considered accurate when their work can meet the accuracy level proposed by the rubric. The highest accuracy level of the students' summary writing is when they can sum up all statements which are verified by the source, and they will get the lowest accuracy level when they state the statements outside the information of the source.

c. Paraphrasing: to achieve this criterion, high vocabulary mastery is needed. From the interview with the lecturer, paraphrasing is being the first top criterion in assessing the students' summary writing. Most of the analytical rubric in terms of summary writing has this kind of criteria. If the students have the ability of paraphrasing, it is believed that their summary writing skill has been $50 \%$ good because in achieving good paraphrasing skills, the other criteria usually follow behind. This criterion is essential to improve the students' conciseness in terms of writing. However, a good summary writing commonly consists of only a few sentences. It is supported by Oshima and Hogue (1999) who state that summarizing is compressing large amounts of information into the fewest possible sentences. It stands to reason that the length of sentences in summary writing also needs to be concerned. Their paraphrasing ability is considered good when they can state no more than four words in a row taken directly from the source. In contrast, their work will be categorized as bad paraphrasing when there are three or more sentences contained more than 4 words in a row taken directly from the source. An example is in the following:

- Original source: Those teachers also had the experiences of using many English textbooks over their experiences, including the two textbooks which were analyzed in this research.

- The students' statements: Those teachers also had the experience of using many English textbooks about their experiences, including the two textbooks analyzed in this study.

The student's statement above is categorized as bad paraphrasing since she/he restates almost all words from one sentence. A good paraphrasing sentence can be seen as follows:
- Good paraphrasing: Many English textbooks indicated their experiences are used by the teachers, including the current textbooks.

d. Focus: as Frey et al. (2003) has stated clearly, summarizing is intended to convey correct information efficiently so that the reader can learn the main idea essential details through a piece that is much shorter than the source. To summarize means to cover the whole information from the source into fewer sentences without running from the main point or the focus of the source itself. Staying on the focus of the source is truly fundamental in summarizing the writing. The lecturer, in this case, asserted that just because the sentence or the writing is short, it does not mean that the summary writing is good if the main idea from the source is not included. So that in writing summary, we have to make all of these criteria balance. Most of the students wrote down a summary writing outside information from the source. They did not focus on the main idea, in fact, they only stated what they got from the source without really concerning what the article is about. As stated in summary writing's rubric above, if their writing consists of the main idea and important details only, their work is categorized as good summary writing. The problem is, they were still confused about differentiating important and unimportant details of the information.

e. Conventions: This is the last criteria the students need to be careful the most. No matter how short the summary is, how good the vocabulary choice is, and how high the ability in compressing the idea is, if they write it down in an ungrammatical way, the writing will be meaningless and unreadable. Moreover, no matter how good the grammar is, if it is written in the wrong spelling, it can be vague and pointless. Also, no matter how excellent the grammar and the spelling are, if the students put wrong punctuations, it will be useless, people will not understand what this writing exactly is about. As the lecturer has said, in summary, writing, the students need to build a correlation between one criterion to other criteria. All criteria stated on the table need to be balanced to achieve a good summary writing. This item is one of the big problems of the students in all of the writing types. A good summary writing is indicated by having no errors in all of punctuations, grammar, and spelling. However, the teacher said that the most common problem of this type is error grammar. As we know that writing is the most difficult productive skill since it needs accurate grammar to make writing readable. Most of the students did not care about grammar. They mostly missed being or linking verbs in their work. They also had not completely understood about the use of gerund since the teacher mostly found verb one after conjunction. Hence, besides grammar, their punctuation and spelling were already good enough. 
Why is this analytical rubric selected to the best tool in assessing the students' summary writing skill?

Stepping back again to the analysis of the very first criteria, from the interview with the lecturer, it was found that the students mostly used ten or even more sentences in writing a summary for the first time. It happened because they do not pay attention to the length. After all, they only write what they have experienced without really concerning the length of sentences. It was also found that the students got confused in paraphrasing the sentences so there are several sentences stated out of the information from the source. They also did not pay attention to the conventions since they were only concerned about how to restate the idea from the source into their work.

In another day, the lecturer gave them the same task (summary writing) with a different topic. However, on this day, before giving the students the task, the lecturer showed them the analytical rubric itself. It helped the students to be aware in enhancing their ability to write a summary because they know what criteria they have to achieve. The students started to be careful about what they write since knowing what criteria they were going to accomplish. Amazingly, after displaying the scoring rubric to the students and giving them another task of summary writing, they gained their score up. It means that they started to be aware of the criteria in summarizing.

Besides, the lecturer selected this rubric to be the best tool in assessing students' summary writing skill is because the criteria of this scoring rubric is giving correlation and related to each other. It can be proved that to make the sentences shorter, the ability of paraphrasing needs to be good. Furthermore, to make the writing accurate, the focus of the source has to be mentioned and correct. Also, to make these four criteria understandable and readable, the convention consists of grammar, punctuation, and spelling need to be mostly concerned.

After analyzing and reflecting the data, this is the reason why this rubric is selected to be the most suitable assessment in scoring the students' summary writing, it is because this kind of rubric can improve the students' achievement in terms of summary writing because they are aware of the criteria they need to accomplish, and it is also because the criteria of this analytical rubric are having a relationship to each other. Furthermore, the criteria included in this rubric are also appropriate to measure the students' ability in summary writing.

\section{CONCLUSION}

After doing the research and find the results, the problems found by the teacher during summary writing's class were (1) the students did not pay attention to the length of their work, they mostly provided more than 11 sentences in summarizing the articles, (2) the students' work was still lack of accuracy since their most statements cited outside the information of the source, (3) their paraphrasing was still low since they did not concern about this category, (4) the focus of the source was less stated since they were confused differentiating the most important information, and (5) the conventions, especially grammar, were still not perfect. Some of them were still lack of grammar knowledge.

However, after the teacher conducted the summary writing's rubric, there are several points summarized the writer can draw as the conclusion, such as (1) the findings in the study imply that this rubric can be considered as a tool to improve students' summary writing skill, (2) through the result and discussion, it can be concluded that students get the positive awareness to achieve a good writing skill based on the criteria given, and (3) the students also get the improvement in critical thinking skill when they try to write a summary by balancing all of the criteria.

\section{REFERENCES}

Ausubel, D. G. (1963). Cognitive structure and the facilitation of meaningful verbal learning. Journal of Teacher Education, 14(2), 217-222. doi: 10.1177/002248716301400220

Foong, K. P. (2017). Teaching writing: A look at purposes, writing tasks, and implications. The English Teacher, 9.

Frey, N., Fisher, D., Hernandez, T. (2003). "What's the gist?" summary for struggling adolescent writers. Voice from the Middle, 11(2), 43-49.

Harmer, J. (2007) The Practice of English Language Teaching. (4th ed.) London: Longman.

Hendrian, Y. Assessing the Accuracy of College Students' Summary Writing. Passage, 1(2), 81-88.

Kusmawati, J. A. (2019). The Influence of Rubrics and Peer Assessment on Students' Works via Google Platform International Journal Pedagogy of Social Studies. 3(2), 93-99.

Mozaffari, H. (2013). An analytical rubric for assessing creativity in creative writing. Theory and Practice in Language Studies. 3(12), 2214-2219. doi: 10.4304/tpls.3.12.2214-2219

Oshima, A. \& Hogue, A. (1999). Writing Academic English. New York: Longman.

Spelkova, I., \& Hurst, N. (2008). Teachers' attitudes to skill and writing process in Latvia and Portugal. The APPI Journal, 8(1).

Wichadee, S. (2014). Developing reading and summary writing abilities of EFL undergraduate students through transactional strategies. Research in Education. 92(1), 59-71. doi: 10.7227/rie.0005 